\title{
Emergency pulmonary resection in massive hemoptysis: analysis of 39 patients
}

\author{
Serkan Yazgan, Ahmet Ucvet, Kenan Can Ceylan, Canberk Heskiloglu, Banu Yoldas, Serpil Sevinc \\ Department of Thoracic Surgery, Health Sciences University, Dr Suat Seren Chest Diseases and Surgery \\ Training and Research Hospital, Izmir, Turkey
}

Kardiochirurgia i Torakochirurgia Polska 2021; 18 (4): 203-209

\begin{abstract}
Introduction: The mortality of massive hemoptysis is high, and it is important to make quick decisions. Emergency pulmonary resection continues to be a mandatory option when conservative methods cannot prevent massive hemoptysis, as it is lifethreatening.

Aim: We report our experience with patients undergoing pulmonary resection for massive hemoptysis.

Material and methods: This study is a retrospective analysis of 39 consecutive patients who were referred to the thoracic surgery intensive care unit of a tertiary hospital for massive hemoptysis and underwent emergency pulmonary resection by thoracotomy between January 2007 and March 2021.

Results: Male dominance with an average age of 49.3 (16-70) and a gender ratio of 3.3 were recorded. The most common underlying cause of massive hemoptysis was bronchiectasis $(n=16)$. Bronchiectasis was followed by aspergilloma $(n=11)$ and previous tuberculosis $(n=8)$. Bronchial artery embolization was performed in $20.5 \%$ of patients. Twenty-nine $(74.4 \%)$ lobectomies, 7 (17.9\%) pneumonectomies, and 3 (7.7\%) segmentectomies were performed. The mean operation duration was $253.6 \pm 71$ minutes. Recurrent hemoptysis was recorded in $7.7 \%$ of patients. Postoperative life-threatening complications were seen in $28.2 \%$, while minor complications developed in $28.2 \%$ of patients. Postoperative complications were significantly higher in patients with tuberculosis sequelae $(p=0.006)$. Hospital mortality was observed in $5.1 \%$ of patients.

Conclusions: The postoperative period is more problematic in patients with a history of tuberculosis who undergo emergency pulmonary resection due to massive hemoptysis. Despite this, emergency pulmonary resection is a curative method with acceptable postoperative complications and low hospital mortality in all tolerant patients according to their clinical condition.
\end{abstract}

Key words: hemoptysis, pneumonectomy, bronchiectasis, tuberculosis, pulmonary aspergillosis.

\section{Introduction}

Massive hemoptysis, or in other words, life-threatening hemoptysis used in the literature, is considered to be a medical condition that requires emergency intervention with a high mortality rate [1]. Although minor hemoptysis is common, massive hemoptysis is much less common, and most physicians are not ready to manage this clinical picture. However, critical first steps in treatment should be implemented immediately by quickly determining the hemorrhage source and the underlying etiology.

The definition of massive hemoptysis in the literature has always been different. Definitions were made variably based on criteria such as hemorrhage volume per hour, total hemorrhage volume for 24 hours, abnormal gas exchange, or presence of hemodynamic instability [2-4]. It is also difficult to estimate the total amount of hemoptysis, as hemorrhage often begins before hospital admission. Therefore, it is most appropriate to define massive hemoptysis since it is life-threatening, and can cause airway obstruction and asphyxia. When categorized according to the amount of hemoptysis, thresholds ranging from $100 \mathrm{ml} / 24$ hours to $1000 \mathrm{ml} / 24$ hours are recommended to define massive hemoptysis [4-8].

It is estimated that $5-14 \%$ of patients with hemoptysis might have life-threatening massive hemoptysis [1]. When massive hemoptysis is managed conservatively, the mortality rate is $50-100 \%[4,9]$. The cause of death is usually excessive hemorrhage or shock and asphyxia caused by airway obstruction. In 36\% of the patients treated medically, recurrent hemoptysis develops within the first 6 months, and $45 \%$ of these are fatal [4]. Mortality rates of surgery in patients with massive hemoptysis vary between $7-18 \%$ $[4,10,11]$. When emergency surgery is performed in the presence of active hemoptysis, this rate increases to $40 \%$ [9].

Conservative medical treatment, endobronchial control measures (balloon tamponade, endobronchial iced saline

Address for correspondence: Assoc. Prof. Serkan Yazgan, Department of Thoracic Surgery, Health Sciences University, Dr Suat Seren Chest Diseases and Surgery Training and Research Hospital, Izmir, Turkey, e-mail: serkanyazgan@gmail.com Received: 1.06.2021, accepted: 12.08 .2021$. 
lavage), bronchial artery embolization (BAE), and surgical treatment (pulmonary resection) are among the reported treatment modalities for massive hemoptysis [12].

\section{Aim}

In this article, we share the results of our patients who underwent emergency pulmonary resection due to massive hemoptysis.

\section{Material and methods}

This retrospective study was conducted at Health Sciences University Izmir Dr Suat Seren Chest Diseases and Surgery Training and Research Hospital, Department of Thoracic Surgery. The study protocol was approved by the Institutional Review Board (IRB date/no: 26.03.2021/26-18) for Human Subjects Research and Ethics Committee of Health Sciences University Izmir Dr Suat Seren Chest Diseases and Surgery Training and Research Hospital under the principles of the Helsinki Declaration.

We retrospectively reviewed the medical records of 39 patients who underwent emergency anatomic pulmonary resection for massive hemoptysis between January 2007 and March 2021. When a patient with hemoptysis was admitted to the hospital's emergency department, a pulmonologist conducted the first assessment. The pulmonologist made the primary diagnosis after examining a chest X-ray, computed tomography (CT) scan, and basic laboratory tests, then evaluated whether symptoms could be controlled with nonsurgical treatment. The cut-off for massive hemoptysis was defined as $>200 \mathrm{ml} /$ hour or $>600 \mathrm{ml} /$ day. A plastic vomit bag with a volume of $1500 \mathrm{ml}$ was used to monitor the amount of hemoptysis. All patients were treated with the same method in conservative treatment. Antitussive, sedative, hemostatic drugs, and broad-spectrum antibiotics were given to the patients who were taken to absolute bed rest in the semi-Fowler position, and the amount of hemoptysis was followed. Blood transfusion was initiated when the hemoglobin level was below $10 \mathrm{~g} / \mathrm{dl}$ or hematocrit was below $30 \%$.

In the event of conservative treatment failure and uncontrolled massive hemorrhage, the patient was taken to the thoracic surgery intensive care unit, and rigid bronchoscopy was performed. Localization of hemorrhage and the endobronchial system were evaluated. Simultaneous interventional methods such as cold saline lavage, adrenaline $(0.1 \%)$ administration or bronchoscopic balloon tamponade were also used when necessary. If hemorrhage continued, selective intubation was performed with a double-lumen endobronchial tube to isolate and spare the contralateral lung. Patients with refractory hemorrhage and hemodynamically unstable patients underwent emergency pulmonary resection by posterolateral thoracotomy if the lesions were anatomically localized. A respiratory function test could not be performed for the patients in the preoperative evaluation due to severe hemorrhage and instability. Preoperative arterial blood gas analysis was used to evaluate single lung ventilation. Since the total hemoptysis volume is difficult to determine, it was not used as a criterion for determining patients in need of surgery. Surgical tissue samples were examined regarding pathological and microbiological features, and the definite diagnoses were categorized accordingly. When there was more than one diagnosis causing hemoptysis in a patient, each diagnosis was considered separately. All medical records, surgery notes, and postoperative follow-up records were reviewed. The patients' latest status was updated by examining the National Population Registration System, and the patients who died were identified.

In the analysis of patients with comorbidities, chronic lung disease, cardiovascular diseases, diabetes mellitus, accompanying extrapulmonary malignancies, hematological diseases, and thyroid disorders were recorded. Empyema, bronchopleural fistula (BPF), respiratory failure, intrathoracic hemorrhage, pulmonary embolism, and wound detachment requiring re-thoracotomy detected in the postoperative period were defined as life-threatening complications. Prolonged air leak, sputum retention requiring bronchoscopy, subcutaneous emphysema, and arrhythmia were regarded as minor complications. After the surgical procedure the chest tube was terminated after the air leakage ended with a drainage amount of less than $100 \mathrm{ml} /$ day, and it was thought that the patient could be discharged. Air leak lasting longer than 5 days postoperatively was interpreted as prolonged air leak. Hospital mortality was defined as deaths of patients occurring within 30 days after surgery or before discharge.

\section{Statistical analysis}

The data obtained included medical history, hospital outcomes, and prognosis. Statistical analyses were performed using SPSS software (SPSS, Inc, Chicago, III). Descriptive data were expressed as means, standard deviations, and percentages for qualitative variables. Univariate analyses with postoperative complications were investigated using the $t$-test for continuous variables. A $p$-value of $<0.05$ was considered significant in the comparisons.

\section{Results}

The mean follow-up period of 39 patients with a mean age of 49.3 (16-70) was $50.6 \pm 51.3$ months. Thirty-one (79.5\%) of the patients were alive at the end of the followup period. Thirty $(76.9 \%)$ of the patients were male, and $9(23.1 \%)$ were female. The most common underlying cause of massive hemoptysis was bronchiectasis $(n=16)$, which was followed by aspergilloma $(n=11)$ and previous tuberculosis (TB) $(n=8)$. Other diseases found in the etiology and preoperative characteristics of the included patients are shown in Table I. Eleven (28.2\%) patients had a cavity with a mean diameter of $5.7 \pm 2.1 \mathrm{~cm}$. Eight of these patients had a previous TB history. Hemorrhage originated from the right lung in 19 (48.7\%) patients, while it originated from the left lung in $20(51.3 \%)$ patients. The most common hemorrhage lobe was the left upper lobe (Table II). Blood transfusion with erythrocyte suspension and fresh 
frozen plasma was initiated in 16 (41\%) patients during hemoptysis. Comorbidity was detected in 23 (58.9\%) of the patients. The most common comorbidities were cardiovascular disease in 8 patients and diabetes mellitus in 5 patients. In addition, 7 patients had tuberculosis with completed medical treatment.

Lobectomy was performed in 29 (74.4\%) patients, pneumonectomy in 7 (17.9\%) patients, and segmentectomy in $3(7.7 \%)$ patients (Table III). The mean operation duration was $253.6 \pm 71$ minutes (Table IV). During the operation of $25(64.1 \%)$ patients, conditions that complicated the surgical intervention were encountered. Seventeen (43.5\%) of the patients had tight adhesions between the lung and surrounding tissues, especially with the chest wall. In 6 (15.4\%) patients, it was observed that the lung formed adhesions at the fusion level. While 1 (2.6\%) patient required a clamp on the right main bronchus due to intense and active hemorrhage, 1 (2.6\%) patient required bronchoscopy because of desaturation due to hemorrhage during the operation. The mean postoperative intensive care unit stay duration was $1.9 \pm 2.5$ days, the mean postoperative duration of hospitalization was $11.4 \pm 11.2$ days, and the total duration of hospitalization was $17 \pm 14.2$ days.

The pathological stages and tumor types of 4 patients diagnosed with non-small cell lung cancer (NSCLC) were Stage IB (T2aNOMO) adenocarcinoma, Stage IIB (T3NOMO) large cell carcinoma, Stage IIIA (T2bN2M0) adenocarcinoma, and Stage IIIA (T4NOMO) adenocarcinoma. In the stage IB patient, left pneumonectomy was performed because almost all of the left lung parenchyma was covered with giant bullae, and systematic mediastinal lymph node dissection (MLND) was performed after the diagnosis was malignant with frozen section examination during the operation. The patient completed the second year of follow-up without any problems. The Stage IIB patient was diagnosed preoperatively by bronchoscopy, but the patient underwent an emergency operation due to the sudden hemorrhage of $400 \mathrm{ml}$ and left pneumonectomy, and MLND was performed. The patient completed the $30^{\text {th }}$ month of follow-up without any problems. A mass in the upper lobe of the right lung was detected preoperatively in a Stage IIIA (T2bN2M0) patient, who was also examined by F-18 fluorodeoxyglucose (FDG) positron emission tomography/computed tomography (PET/ $\mathrm{CT}$ ) and was found radiologically compatible with multiple N2 diseases. However, due to sudden and life-threatening hemoptysis, right upper lobectomy and MLND were urgently performed. The patient is in the $14^{\text {th }}$ month of follow-up and is receiving oncological treatment for local and systemic recurrence. The other Stage IIIA (T4NOMO) patient was diagnosed preoperatively and staged radiologically. However, due to sudden massive hemoptysis that could not be prevented by conservative methods, left pneumonectomy and MLND were urgently performed. Multiple brain metastases were detected in the $18^{\text {th }}$ month of follow-up, and the patient died at the end of the 19-month follow-up.

In 1 of the 2 patients for whom intrapulmonary foreign bodies were detected, the chicken bone that was aspirated
Table I. Preoperative factors in patients with massive hemoptysis

\begin{tabular}{|c|c|c|c|}
\hline Variables & $\begin{array}{c}\text { All } \\
\text { patients } \\
(n=39)\end{array}$ & $\begin{array}{l}\text { Emergency } \\
\text { resection } \\
(n=31)\end{array}$ & $\begin{array}{c}\text { Emergency } \\
\text { resection } \\
\text { with BAE } \\
(n=8)\end{array}$ \\
\hline Age [years] ${ }^{a}$ & $49.3 \pm 14.6$ & $48.6 \pm 15$ & $51.9 \pm 13.3$ \\
\hline Gender $(M / F)$ & $30 / 9$ & $24 / 7$ & $6 / 2$ \\
\hline $\begin{array}{l}\text { Cavity size }[\mathrm{cm}] \\
(n=11)\end{array}$ & $5.7 \pm 2.1$ & $6.4 \pm 2.2$ & $4.5 \pm 1.3$ \\
\hline Comorbidity $(n)^{\mathrm{b}}$ & $23(58.9)$ & $16(51.6)$ & $7(87.5)$ \\
\hline INR & $1.05 \pm 0.08$ & $1.05 \pm 0.08$ & $1.02 \pm 0.08$ \\
\hline aPTT [s] & $29.7 \pm 3.7$ & $30.2 \pm 3.9$ & $28.1 \pm 2.7$ \\
\hline \multicolumn{4}{|l|}{ Etiology: } \\
\hline Bronchiectasis & $16(41.0)$ & $14(45.2)$ & $2(25.0)$ \\
\hline Aspergilloma & $11(28.2)$ & $6(19.3)$ & $5(62.5)$ \\
\hline Previous TB & $8(20.5)$ & $5(16.1)$ & $3(37.5)$ \\
\hline Lung carcinoma & $4(10.2)$ & $4(12.9)$ & - \\
\hline Bronchogenic cyst & $2(5.1)$ & - & $2(25.0)$ \\
\hline $\begin{array}{l}\text { Intrapulmonary } \\
\text { foreign body }\end{array}$ & $2(5.1)$ & $2(6.4)$ & - \\
\hline $\begin{array}{l}\text { Interstitial lung } \\
\text { disease }\end{array}$ & $2(5.1)$ & $1(3.2)$ & $1(12.5)$ \\
\hline Behcet's disease & $1(2.6)$ & $1(3.2)$ & - \\
\hline $\begin{array}{l}\text { Pulmonary } \\
\text { endometriosis }\end{array}$ & $1(2.6)$ & $1(3.2)$ & - \\
\hline Emphysema & $1(2.6)$ & $1(3.2)$ & - \\
\hline Fibroma & $1(2.6)$ & $1(3.2)$ & - \\
\hline
\end{tabular}

BAE - bronchial artery embolization, ${ }^{a}$ mean \pm standard deviation, ${ }^{b} n(\%)$, INR - international normalized ratio, aPTT - activated partial thromboplastin time, TB - tuberculosis.

Table II. Distribution of hemorrhage focus by lobes

\begin{tabular}{lcc} 
Lobe & Number & $\%$ \\
Upper right & 8 & 20.5 \\
\hline Middle right & 3 & 7.7 \\
\hline Lower right & 8 & 20.5 \\
\hline Upper left & 10 & 25.6 \\
\hline Lingula & 3 & 7.7 \\
\hline Lower left & 7 & 18 \\
\hline
\end{tabular}

Table III. Pulmonary resection types

\begin{tabular}{lcc}
$\begin{array}{l}\text { Type of resection } \\
\text { Pneumonectomy }\end{array}$ & Number $(\%)$ & $\begin{array}{c}\text { Side/lobe } \\
\text { Left }=7\end{array}$ \\
\hline Lobectomy & $29(74.9)$ & $\mathrm{RUL}=7 ; \mathrm{RUL}+\mathrm{RML}=1 ;$ \\
& & $\mathrm{RLL}=6 ; \mathrm{RLL}+\mathrm{RML}=1 ;$ \\
& $\mathrm{RML}=3 ; \mathrm{LUL}=5 ; \mathrm{LL}=3 ;$ \\
& $\mathrm{LLL}+$ Lingulectomy $=3$ \\
\hline Segmentectomy & $3(7.7)$ & Lingula $=2$ \\
& & Right multibasal $=1$ \\
\hline
\end{tabular}

RUL - right upper lobe, RML - right middle lobe, RLL - right lower lobe, LUL - left upper lobe, LLL - left lower lobe. 
Table IV. Operative variables in patients with massive hemoptysis

\begin{tabular}{|c|c|c|c|}
\hline Variables & $\begin{array}{l}\text { All patients } \\
(n=39)\end{array}$ & $\begin{array}{l}\text { Emergency resection } \\
\qquad(n=31)\end{array}$ & $\begin{array}{l}\text { Emergency resection with BAE } \\
\qquad(n=8)\end{array}$ \\
\hline Duration of operation [min] ${ }^{a}$ & $253.6 \pm 71$ & $257.4 \pm 74.3$ & $241.2 \pm 61.8$ \\
\hline Technical challenge in operation $(n)^{\mathrm{b}}$ & $25(64.1)$ & $20(64.5)$ & $5(62.5)$ \\
\hline Duration of intensive care stay [days] $]^{a}$ & $1.9 \pm 2.5$ & $1.8 \pm 2.3$ & $2.6 \pm 3.3$ \\
\hline Duration of postoperative stay [days] ${ }^{a}$ & $11.4 \pm 11.2$ & $11.3 \pm 11.2$ & $11.4 \pm 12$ \\
\hline Duration of hospitalization [days] $]^{\mathrm{a}}$ & $17 \pm 14.2$ & $17.4 \pm 14.8$ & $15.4 \pm 12.3$ \\
\hline Recurrent hemorrhage $(n)^{\mathrm{b}}$ & $3(7.7)$ & $1(3.2)$ & $2(25.0)$ \\
\hline Postoperative complication $(n)^{\mathrm{b}}$ & $11(28.2)$ & $8(25.8)$ & $3(37.5)$ \\
\hline Hospital mortality $(n)^{\mathrm{b}}$ & $2(5.1)$ & $2(6.5)$ & $0(0)$ \\
\hline
\end{tabular}

aMean \pm standard deviation, ${ }^{b} n(\%)$.

10 years ago was removed from the resected lobe, while gossypiboma was found in the other patient. The patient who had gossypiboma had a thoracotomy history due to trauma 20 years ago.

Preoperative BAE history was detected in 8 (20.5\%) of the cases. Seven of these patients had recurrent hemopty-

Table V. Operative complications

\begin{tabular}{lcl} 
Variable & $\begin{array}{c}\text { Postoperative } \\
\text { complication }\end{array}$ & Mortality \\
Total & 22 & 2 \\
\hline Prolonged air leak ( $\geq 5$ days) & 8 & - \\
\hline Empyema & 3 & - \\
\hline BPF & 2 & - \\
\hline Respiratory failure & 2 & 2 \\
(prolonged intubation) & 2 & - \\
\hline Intrathoracic hemorrhage & 1 & - \\
\hline Pulmonary embolism & 1 & - \\
\hline Sputum retention & 1 & - \\
\hline Wound site detachment & 1 & - \\
\hline Subcutaneous emphysema & 1 &
\end{tabular}

Table VI. Distribution and analysis of complications

\begin{tabular}{|c|c|c|c|c|}
\hline \multicolumn{2}{|l|}{ Variable } & \multicolumn{2}{|c|}{ Complication } & \multirow[t]{3}{*}{$P$-value } \\
\hline & & Yes & No & \\
\hline & & $n(\%)$ & $n(\%)$ & \\
\hline \multirow{2}{*}{$\begin{array}{l}\text { Surgical } \\
\text { intervention }\end{array}$} & Pneumonectomy & $4(57.1)$ & $3(42.9)$ & \multirow[t]{2}{*}{1} \\
\hline & Others & $18(56.2)$ & $14(43.8)$ & \\
\hline \multirow[t]{5}{*}{ Diagnosis } & Bronchiectasis & $9(56.2)$ & $7(43.8)$ & 1 \\
\hline & Aspergilloma & $9(81.8)$ & $2(18.2)$ & 0.07 \\
\hline & Previous TB & $8(100)$ & $0(0)$ & 0.006 \\
\hline & Lung carcinoma & $1(25.0)$ & $3(75.0)$ & 0.3 \\
\hline & Others & $2(25.0)$ & $6(75.0)$ & 0.06 \\
\hline \multirow[t]{2}{*}{ BAE } & Yes & $4(50.0)$ & $4(50.0)$ & \multirow[t]{2}{*}{0.71} \\
\hline & No & $18(58.1)$ & $13(41.9)$ & \\
\hline \multirow[t]{2}{*}{ Age } & $<50$ & $11(61.1)$ & $7(38.9)$ & \multirow[t]{2}{*}{0.75} \\
\hline & $\geq 50$ & $11(52.4)$ & $10(47.6)$ & \\
\hline
\end{tabular}

$\mathrm{TB}$ - tuberculosis, BAE - bronchial artery embolization. sis, and 1 patient had persistent hemoptysis. Recurrent hemoptysis was recorded in 3 (7.7\%) patients after pulmonary resection, and 2 of them were patients who previously had BAE. While 1 of the 3 patients with recurrent hemoptysis died in the postoperative period, hemoptysis was treated with completion pneumonectomy in 1 and medical treatment alone was sufficient for the other patient. Postoperative life-threatening complications developed in 11 (28.2\%) patients, while minor complications developed in 11 (28.2\%) patients. The most common problem among postoperative complications was prolonged air leak in 8 patients (Table V). When the distribution of postoperative complications by diseases was examined, statistically significant postoperative complications were found in all patients with previous TB history $(p=0.006)$ (Table VI). Because of the complications that developed, re-thoracotomy was performed in $4(10.2 \%)$ patients. Re-operation was required in 2 of these patients due to intrathoracic hemorrhage, 1 due to BPF and 1 due to detachment at the wound site. In our study, there were 2 (5.1\%) patients for whom BPF was found, and the operative pathology of both patients was reported as TB cavity and aspergilloma. No mortality was detected in 7 patients who underwent pneumonectomy. One of the 2 (5.1\%) patients with hospital mortality had a right upper lobectomy, and the other had a middle lobectomy. The patient who died after right upper lobectomy on the $29^{\text {th }}$ postoperative day had prolonged mechanical ventilation due to respiratory failure with subsequent pneumonia. In the patient who underwent middle lobectomy, prolonged mechanical ventilation due to respiratory failure and also recurrent hemoptysis resulted in death on the $9^{\text {th }}$ postoperative day.

\section{Discussion}

In recent years, the rate of massive hemoptysis caused by fungal infections has gradually increased, especially in patients with cavitary lung disease [13]. Most of these are Aspergillus infections, and the cavity is surrounded by enlarged bronchial arteries that are highly susceptible to hemorrhage. 50-90\% of Aspergillus infections with cavity complications can cause massive hemoptysis [14]. Endo et al. [11] detected cavities in $48 \%$ of patients who underwent emergency pulmonary resection due to massive hemoptysis. In our study, the rate of patients for whom a cavity was detected was $28.2 \%$, and a fungal ball accompanied 
Table VII. The most frequent diagnosis, postoperative complications and hospital mortality rates in massive hemoptysis emergency pulmonary resection series

\begin{tabular}{|c|c|c|c|c|c|c|}
\hline Major author [ref.] (year) & Country & $\begin{array}{l}\text { Patients } \\
\text { (n) }\end{array}$ & $\begin{array}{l}\text { The most common } \\
\text { diagnosis }\end{array}$ & $\begin{array}{l}\text { The most common } \\
\text { diagnosis rate (\%) }\end{array}$ & $\begin{array}{l}\text { Postoperative } \\
\text { complications (\%) }\end{array}$ & $\begin{array}{c}\text { Mortality } \\
(\%)\end{array}$ \\
\hline Lee [19] (2000) & Hong-Kong & 27 & Bronchiectasis & 57.4 & 29.6 & 15 \\
\hline Endo [11] (2003) & Japan & 25 & Fungal abscess & 48 & 32 & 4 \\
\hline Ayed [12] (2003) & Kuwait & 27 & Bronchiectasis & 29.6 & 29.6 & 7.4 \\
\hline Metin [20] (2005) & Turkey & 29 & TB & 34.5 & 27.5 & 11.5 \\
\hline Andrejak [10] (2009) & France & 48 & TB & 59 & 71 & 35.4 \\
\hline Alexander [9] (2014) & S. Africa & 61 & TB & 54 & 32.8 & 4.9 \\
\hline Gradica [21] (2014) & Albania & 15 & TB & 37.5 & 26.7 & 4.1 \\
\hline Kiral [22] (2015) & Turkey & 31 & Bronchiectasis & 42 & 25.8 & 6.5 \\
\hline Current study (2021) & Turkey & 39 & Bronchiectasis & 41 & 28.2 & 5.1 \\
\hline
\end{tabular}

TB - tuberculosis.

the cavity in all of them. According to the surgical pathology reports, 8 of these cavities were TB, 2 were bronchogenic cysts, and 1 was cystic bronchiectasis.

Massive hemoptysis may also occur due to lung carcinoma that has an endobronchial component or a cavitary formation [6]. Approximately $20 \%$ of patients with lung carcinoma will experience hemoptysis at some point in its course, but only $3 \%$ present with massive hemoptysis. About $80 \%$ of patients with massive hemoptysis due to malignancy have a history of small sentinel hemorrhage episodes in the previous weeks [6]. Squamous cell carcinoma usually occurs in the central airway, can lead to cavitation, and can reach large sizes. Massive hemoptysis is more common in these tumors than non-squamous carcinomas [13]. However, despite this basic information, 3 of our 4 lung carcinoma patients who underwent emergency resection due to massive hemoptysis had adenocarcinoma, and 1 had large cell carcinoma. Three of our patients had a vegetative tumoral mass in the central airway, and it was the source of hemorrhage. Therefore, left pneumonectomy was performed in these 3 patients. There were no patients in whom oncological treatment was initiated in our lung carcinoma patients. However, especially in recent years, a few studies reported that some new antiangiogenic drugs such as bevacizumab that is used in the treatment of nonsquamous NSCLC could lead to life-threatening and severe hemoptysis [15].

Applying interventional procedures such as BAE for hemoptysis arising from systemic bronchial vessels and pulmonary artery occlusion or endovascular stents for hemoptysis originating from pulmonary vessels may allow emergency surgery to be delayed [16]. BAE is the most common endovascular procedure, as bronchial arteries are responsible for massive hemoptysis requiring treatment in more than $90 \%$ of cases. It instantly controls hemorrhage in $66 \%$ to $90 \%$ of patients [17]. Hence, a planned pulmonary resection can be scheduled, and the patient's cardiopulmonary reserve can be measured. However, although there are different treatment modalities, there is no published guideline for hemoptysis [1]. In massive hemoptysis that cannot be prevented by conservative methods, which is our study subject, sometimes there may not be enough time for interventional procedures, and it may be necessary to make a quick decision for life-saving surgery. With this quick decision made by the thoracic surgeon for pulmonary resection, sometimes it may not be possible to perform an anatomical resection due to surgical difficulties. In such situations where resection is technically dangerous or difficult, different surgical modalities such as physiological lung exclusion have also been described. Dhaliwal et al. [18] reported the efficacy and safety of surgical ligation of the bronchial and pulmonary artery of the involved lobe or lung in a series of 20 patients with hemoptysis associated with TB. They reported that there was no operative mortality or recurrent hemoptysis through this surgical technique.

When the last two decades of data are reviewed in the literature, the postoperative complication rate has been reported between $25.8 \%$ and $71 \%$, and hospital mortality between $4 \%$ and $35.4 \%$ in patients undergoing emergency pulmonary resection due to massive hemoptysis [9-12, 19-22] (Table VII). The reason for this wide range of postoperative complication rates is that different complication groups were addressed in each study. In our study, we evaluated our complications in two different groups to make a comparison with the literature. The rate of both life-threatening complications and minor complications was $28.2 \%$. Considering that $58.9 \%$ of our patients had significant respiratory and cardiac comorbidities, we can say that the rate of postoperative complications occurring after emergency pulmonary resection is at an acceptable level. This rate is, of course, higher in studies that include a larger group of complications in the analysis. For example, in a study in which emergency pulmonary resection was performed in 48 patients due to massive hemoptysis, postoperative complications were reported in 32 (71\%) patients [10]. Considering the results of the literature, it can be said that there is a wide range of in-hospital mortality. The most important reason for this is that the definition of massive hemoptysis was handled differently in each study, and there was no consensus on the amount of hemorrhage. Also, in some studies, patients who were operated on while the hemorrhage was continuing and those who 
were operated on a planned basis after the hemorrhage was controlled were not separated and were evaluated together. All patients discussed in our study were patients whose hemoptysis process continued despite medical treatment and who underwent unplanned surgery. Andrejak et al. [10] drew attention to this issue and reported that the postoperative complication rate decreased from $71 \%$ to $28 \%$, and hospital mortality decreased from $35 \%$ to $4 \%$ in hemoptysis patients who could undergo scheduled surgery after the hemorrhage was controlled. This is an indication that pulmonary resection performed without stopping the hemorrhage is very risky. However, in our study, hospital mortality was $5.1 \%$, and despite this detail in the literature, it shows that emergency resections can be performed with lower mortality in massive hemoptysis with the help of developing surgical technology. Some poor prognostic factors have been described in patients with massive hemoptysis in the literature [6]. Accordingly, one of the most important factors that increase mortality is the excessive amount of hemorrhage. Aspiration of heavy hemorrhage to the healthy lung side and subsequent respiratory failure can lead to death. In massive hemoptysis, rapid action should be taken to protect the lung from aspiration, and rigid bronchoscopy should be performed by taking the patient to the operating room. However, it may be difficult to determine which lobe (or maybe from which lung only) the hemorrhage originated with bronchoscopy performed while heavy hemorrhage is continuing. In such a case, there will undoubtedly be large amounts of blood in both bronchial systems, and sometimes a complete evaluation will not be possible. Our 2 patients who died were the 2 patients with the highest amount of hemorrhage. In the first of these patients, $600 \mathrm{ml}$ of hemorrhage developed suddenly in the hospital after the hospitalization with hemoptysis for a while, and 6 units of blood replacement were required. Surgery was recommended to the patient, who had a TB history and a $7 \mathrm{~cm}$ cavity in the right upper lobe with a fungus ball in it, but the patient refused surgical treatment. For this reason, BAE was performed, but the patient was subjected to an emergency operation due to the massive hemorrhage. During the period until the surgery, aspiration occurred in the contralateral lung, and the patient was intubated for a long time due to respiratory failure in the postoperative period. The patient died on the $29^{\text {th }}$ postoperative day due to subsequent pneumonia. The other patient was referred to our hospital while being followed up in another hospital with hemoptysis. The patient had $1000 \mathrm{ml}$ of hemorrhage in the first hour and then $2000 \mathrm{ml}$ in the first 8 hours in total. In the preoperative period, 4 units of erythrocyte suspension and 4 units of fresh frozen plasma were given. Thorax CT revealed bronchiectasis in the middle lobe and findings of aspiration in the contralateral lung. Middle lobectomy was performed in the patient, who had urgent rigid bronchoscopy but failed to obtain effective results due to heavy hemorrhage. Unfortunately, this patient also had postoperative respiratory failure and prolonged mechanical ventilation and died on the $9^{\text {th }}$ day. Crocco et al. [7] reported a $71 \%$ mortality rate in patients who lost more than $600 \mathrm{ml}$ of blood in 4 hours, a $22 \%$ mortality rate in patients who bled more than $600 \mathrm{ml}$ in 4-16 hours, and a 5\% rate in those with $600 \mathrm{ml}$ of hemoptysis within 16-48 hours, and found a direct correlation between hemoptysis rate and mortality rate. Also, hospital mortality was reported as $58 \%$ and $78 \%$ in previous surgical series, which reported that patients with hemorrhage rates exceeding $1000 \mathrm{ml} / 24$ hours had higher mortality $[3,23]$. Therefore, in all possible patients, stopping acute hemorrhage with conservative treatment methods, performing a meticulous multidisciplinary examination for a definitive diagnosis, localizing the lesion, measuring the patient's respiratory capacity, and then performing pulmonary resection is the most optimal approach. However, if the hemorrhage is severe and continues despite the first interventions, it is necessary to make a surgical resection decision without wasting time and to protect the remaining healthy lung. As the period is prolonged, the risk of aspiration to the healthy lung side increases, and this affects postoperative complications and mortality.

In our study, the majority of the patients were patients with bronchiectasis, aspergilloma, and previous TB diagnosis. This patient group has potential difficulties regarding the operation. Indeed, $64.1 \%$ of our patients experienced some technical difficulties during the operation. Many of these difficulties were due to the severe adhesions the lung forms with the surrounding tissues. This situation also led to the prolongation of the operation time. In our study, we found that the mean operation duration was $253.6 \pm 71$ minutes (between 125 and 405 minutes). Zhang et al. [24] performed emergency anatomical lung resection in 36 patients with pulmonary TB and massive hemoptysis. Their results were similar to our results; the mean operation duration was $254 \pm 58$ minutes (150-390 minutes). They also reported that the mean blood loss during surgery was 877 $\pm 510 \mathrm{ml}$ (100-3000 ml). Endo et al. [11], on the other hand, determined the mean operation duration as 285 minutes (90-540 minutes) in their study. They reported a mean operative blood loss of $980 \mathrm{ml}(100-5200 \mathrm{ml})$.

When we examined the risk factors for postoperative complications, we found that patients with proven TB diagnosis in the past had higher risk $(p=0.006)$. BPF developed in 2 of these patients, who underwent left pneumonectomy and right upper lobectomy, and the right upper lobectomy patient underwent re-thoracotomy and completion pneumonectomy. The BPF rate in our study was $5.1 \%$. Andrejak et al. [10] reported the rate of BPF after resection as $11 \%$ in 48 patients who underwent emergency pulmonary resection with active hemoptysis. In 15 patients for whom massive hemoptysis was controlled, they performed scheduled surgery within 6 months after discharge and found that the rate of BPF in these patients was 20\%. $60 \%$ of these patients who underwent planned surgery had TB. In another patient, who was previously diagnosed with TB, wound detachment developed after deep wound infection, and a re-thoracotomy was performed. In another patient, 
a re-thoracotomy was performed due to intrathoracic hemorrhage. Another patient could not be separated from the mechanical ventilator due to respiratory failure and died with the addition of pneumonia. When looking at this table, it should be stated that the postoperative course of TB and aspergilloma association is surgically challenging. In the treatment of hemoptysis patients with a fungus ball in the TB cavity, different attempts have been made in recent years. Hemostatic radiotherapy applications are one of them. In the study of Sapienza et al. [25], they reported that they applied 2 Gy, in total 20 Gy radiotherapy 5 days a week in 21 patients with massive hemoptysis who were not suitable for surgical treatment, and that they achieved success in all patients in the early period.

The limitations of this study are, first, the use of a retrospective approach. Secondly, the total amount of massive hemoptysis and its effect on the results were not categorized and evaluated numerically, as some patients were referred to our hospital as intubated, and the amount of pre-hospital hemorrhage was not precisely known. Third, operative blood loss data were not included in the study as they were not documented adequately.

\section{Conclusions}

In patients with massive hemoptysis, those with a TB history have a higher rate of postoperative complications. However, emergency pulmonary resection is an effective treatment option in massive hemoptysis which cannot be prevented by maximum medical treatment or minimally invasive methods in patients whose hemorrhage focus can be localized and pulmonary reserve is suitable. The timing of surgery and the type of resection should be chosen appropriately according to the severity of hemoptysis and underlying diseases. This report shows acceptable rates of postoperative complications and low hospital mortality associated with emergency pulmonary resection in massive hemoptysis.

\section{Disclosure}

The authors report no conflict of interest.

\section{References}

1. Kathuria H, Hollingsworth HM, Vilvendhan R, Reardon C. Management of life-threatening hemoptysis. J Intensive Care 2020; 8: 23.

2. Hirshberg B, Biran I, Glazer M, Kramer MR. Hemoptysis: etiology, evaluation, and outcome in a tertiary referral hospital. Chest 1997; 112: 440-444.

3. Corey R, Hla KM. Major and massive hemoptysis: reassessment of conservative management. Am J Med Sci 1987; 294: 301-309.

4. Knott-Craig CJ, Oostuizen JG, Rossouw G, Joubert JR, Barnard PM. Management and prognosis of massive hemoptysis. Recent experience with 120 patients. J Thorac Cardiovasc Surg 1993; 105: 394-397.
5. Wigle DA, Waddell TK. Investigation and management of massive hemopty sis. In: Pearson's Thoracic and Esophageal Surgery. $3^{\text {rd }}$ ed. Pearson FG, Patterson GA, Cooper JD (eds). Churchill Livingstone Elsevier, Philadelphia 2008; 444-454.

6. Radchenko C, Alraiyes AH, Shojaee S. A systematic approach to the management of massive hemoptysis. J Thorac Dis 2017; 9: S1069-S1086.

7. Crocco JA, Rooney JJ, Fankushen DS, DiBenedetto RJ, Lyons HA. Massive hemoptysis. Arch Intern Med 1968; 121: 495-498.

8. Halezeroğlu S, Okur E. Thoracic surgery for hemoptysis in the context of tuberculosis: what is the best management approach? J Thorac Dis 2014; 6: 182-185.

9. Alexander GR. A retrospective review comparing the treatment outcomes of emergency lung resection for massive haemoptysis with and without preoperative bronchial artery embolization. Eur J Cardiothorac Surg 2014; 45: 251-255.

10. Andrejak C, Parrot A, Bazelly B, Ancel PY, Djibré M, Khalil A, Grunenwald D, Fartoukh M. Surgical lung resection for severe hemoptysis. Ann Thorac Surg 2009; 88: 1556-1565.

11. Endo S, Otani S, Saito N, Hasegawa T, Kanai Y, Sato Y, Sohara Y. Management of massive hemoptysis in a thoracic surgical unit. Eur J Cardiothorac Surg 2003; 23: 467-472.

12. Ayed A. Pulmonary resection for massive hemoptysis of benign etiology. Eur J Cardiothorac Surg 2003; 24: 689-693.

13. Jin F, Li Q, Bai C, Wang H, Li S, Song Y, Zeng Y, Zhou R, Li W, Hu C, Zhang J, Zhou $\mathrm{H}$, Zhang $\mathrm{H}$. Chinese expert recommendation for diagnosis and treatment of massive hemoptysis. Respiration 2020; 99: 83-92.

14. Kokkonouzis I, Athanasopoulos I, Doulgerakis N, Tsonis G, Lampaditis I, Saridis N, Skoufaras V. Fatal hemoptysis due to chronic cavitary pulmonary aspergillosis complicated by nontuberculous mycobacterial tuberculosis. Case Rep Infect Dis 2011; 2011: 837146.

15. Goto K, Endo M, Kusumoto M, Yamamoto N, Ohe Y, Shimuzu A, Fukuoka M Bevacizumab for non-small-cell lung cancer: a nested case-control study of risk factors for hemoptysis. Cancer Sci 2016; 107: 1837-1842.

16. Khalil A, Parrot A, Nedelcu C, Fartoukh M, Marsault C, Carette MF. Severe hemoptysis of pulmonary arterial origin: signs and role of multidetector-row CT angiography. Chest 2008; 133: 212-219.

17. Larici AR, Franchi P, Occhipinti M, Contegiacomo A, del Ciello A, Calandriello L, Storto ML, Marano R, Bonomo L. Diagnosis and management of hemoptysis. Diagn Interv Radiol 2014; 20: 299-309.

18. Dhaliwal RS, Saxena P, Puri D, Sidhu KS. Role of physiological lung exclusion in difficult lung resections for massive hemoptysis and other problems. Eur J Cardiothorac Surg 2001; 20: 25-29.

19. Lee TW, Wan S, Choy DK, Chan M, Arifi A, Yim AP. Management of massive hemoptysis: a single institution experience. Ann Thorac Cardiovasc Surg 2000; 6: 232-235.

20. Metin M, Sayar A, Turna A, Solak O, Erkan L, Dinçer SI, Bedirhan MA, Gürses A. Emergency surgery for massive haemoptysis. Acta Chir Belg 2005; 105 639-643.

21. Gradica F, Argjiri Dh, Lisha L, Kokici F, Cami A, Vata L, Ymeraj Z, Leka A, Hafizi $\mathrm{H}$. Management of massive hemoptysis: a single institution experience. Anglisticum J 2014; 3: 101-106.

22. Kiral H, Evman S, Tezel C, Alpay L, Lacin T, Baysungur V, Yalcinkaya I. Pulmonary resection in the treatment of life-threatening hemoptysis. Ann Thorac Cardiovasc Surg 2015; 21: 125-131.

23. Garzon AA, Gourin A. Surgical management of massive hemoptysis: a tenyear experience. Ann Surg 1978; 187: 267-271.

24. Zhang Y, Chen C, Jiang G. Surgery of massive hemoptysis in pulmonary tuberculosis: immediate and long-term outcomes. J Thorac Cardiovasc Surg 2014; 148: 651-656.

25. Sapienza LG, Gomes MIL, Maliska C, Norberg AN. Hemoptysis due to fungus ball after tuberculosis: a series of 21 cases treated with hemostatic radiotherapy. BMC Infect Dis 2015; 15: 546. 